\title{
로봇기반 승마 시뮬레이터가 노인의 유산소성 운동과 심리적 요인에 미치는 영향
}

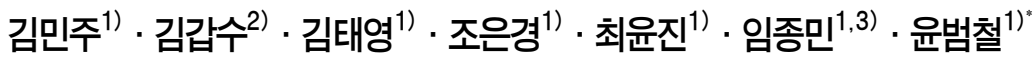

1) 고려대학교 2) 제주한라대학교 3) 군장대학교

\begin{abstract}
Min Joo Kim · Kabsu Kim · TaeYeong Kim • Eunkyoung Jo · Yoon-Jin Choi · Jong-min Lim • BumChul Yoon. The Effect of Robot Based Horse Riding Simulator in Perceived Psychological Factors and Energy Expenditure for the Elderly. KINESIOLOGY, 2015, 17(4): 21-29. [PURPOSE] Horse riding simulator has been developed as a substitute of horse-back riding to compensate poor accessibility and economic feasibility. The effects of a horse riding simulator for young adults have been investigated. However, it has been little known about the psychological and physiological benefits of exercise using a horse riding simulator for the elderly compared with young adults. The purpose of this study was to analyze changes of perceived psychological factors and energy expenditure in young adults and the elderly during riding a horse riding simulator producing similar gait patterns of the horse such as walk, slow trot, and fast trot. [METHODS] The participants were eighteen adults(age: $26.4 \pm 4.2 \mathrm{yrs}$, height: $168.9 \pm 9.2 \mathrm{~cm}$, weight: $63.4 \pm 10.8 \mathrm{~kg}$ ) and seventeen elderly people(age: $68.8 \pm 5.5 \mathrm{yrs}$, height: $160.8 \pm 8.4 \mathrm{~cm}$, weight: $65.0 \pm 10.1 \mathrm{~kg})$. We measured perceived task enjoyment and difficulty, oxygen uptake, and energy expenditure using VAS and pulmonary gas exchange measurement with respect to gait pattern and age difference. The participants rode the simulator in 15 minutes for each gait pattern, respectively. The participants were asked to mark perceived task enjoyment and difficulty by themselves on the $10 \mathrm{~cm}$-line after each gait pattern. We analyzed using the last 10 minutes of gas analysis data for oxygen uptake and MET. [RESULTS] There were significant differences on perceived task enjoyment and difficulty, oxygen uptake, and energy expenditure among gait patterns. There were statistically significant difference in perceived task enjoyment between walk and fast $\operatorname{trot}(p<.05)$, walk and slow $\operatorname{trot}(p<.05)$. Also there were significant difference in perceived difficulty between walk and fast $\operatorname{trot}(p<.05)$, slow trot and fast $\operatorname{trot}(p<05)$. Especially, the elderly was shown greater perceived task enjoyment than young adults $(p<05)$. Oxygen uptake $(F=131.83$, $p<.05)$ and $\operatorname{METs}(F=131.83, p<.05)$ both had significant differences regarding to each gait pattern. [CONCLUSIONS] Riding a horse riding simulator might provide mild exercise effect regardless age difference and this simulator might be utilized to the elderly for safe and attractive exercise program.
\end{abstract}

Key words : horse riding simulator, oxygen uptake, mets, perceived task enjoyment, perceived task difficulty 주요어 : 승마 시뮬레이터, 산소섭취량, METS, 지각된 과제의 재미, 지각된 과제의 어려움

\section{서론}

동물 매개 치료 중 하나인 승마는 기승자의 자세조 절에 관여하는 근육을 말의 독특한 동적인 움직임에 의하여 활성화시켜 근력을 강화시킬 뿐 아니라 근수축 타이밍의 시너지를 향상시키는 등의 효과적인 운동방 법으로 알려져 있다(All et al., 1999; Araujo et al., 2011; Fitzpatrick \& Tebay, 1998). 승마는 노인과 뇌성 마비 등과 같은 장애아동의 자세조절, 균형능력을 향 상시키는 데 긍정적인 역할을 한다(Araujo et al.,
2011; Bertoti, 1988; de Araújo et al., 2013; Homnick et al., 2013; Sterba et al., 2002; Zadnikar \& Kastrin, 2011). 이렇듯 승마는 전신의 협응을 요구하는 운동으 로 이로 인하여 자세조절 능력이 향상될 뿐 아니라 유산소성 운동의 효과(Devienne \& Guezennec, 2000; Westerling, 1983)와 스트레스 완화 등과 같은 심리적 효과를 얻을 수 있다(Bizub et al., 2003; Granados \& Agís, 2011; Kendall et al., 2014).

말 산업 법이 제정된 이후 건강증진에 효과적인 승 마를 대중화하기 위해 국가적인 차원에서 많은 지원과

* 교신저자: yoonbc@korea.ac.kr 
정책이 진행되고 있으나 1 회당 승마 비용이 약 6 만원 내외인 경제적인 부담과 승마장을 직접 방문해야 하는 접근성의 제약이 있으며(Baek et al., 2005; Lee et al., 2011), 낙마로 인한 부상이 발생할 수도 있어 안전사 고에 대한 주의가 요구되기 때문에(Silver, 2002), 일반 인의 승마에 대한 수요는 높지 않은 편이다.

최근에는 이러한 경제 및 안전상의 문제를 보완할 수 있는 대안으로 말의 보행패턴(gait pattern)을 구현 할 수 있는 로봇을 기반으로 한 다양한 승마 시뮬레 이터가 개발되었다(Byeon et al., 2013). 시뮬레이터는 예상하지 못한 움직임을 보일 수 있는 말과 달리 예 측이 가능한 움직임의 형태와 범위, 그리고 속도를 사 용자가 제어할 수 있기 때문에, 이동시간 및 접근성과 같은 물리적 제약과 경제적인 제약을 극복할 뿐만 아 니라 안전하다는 장점이 있다(Hosaka et al., 2010).

선행연구를 통하여 승마 시뮬레이터가 뇌졸중, 파킨 슨 환자 그리고 뇌성마비 아동의 균형 능력과 협응을 향상 시키는데 효과적인 치료 결과를 나타냈으며(Han et al., 2012; Kubota et al., 2006; Lee et al., 2011; Oh et al., 2014; Yoo et al., 2014; Kim et al., 2008), 환자 나 장애인 뿐 아니라 건강한 청 - 장년층의 균형 능력 에도 운동 효과를 보이는 것으로 보고되었다(Baek et al., 2005; Cho et al., 2012). 또한 승마 시뮬레이터를 탑승하게 되면 탑승자는 걷기와 유사한 강도로 에너지 를 소비할 수 있는 저강도의 유산소성 운동의 효과를 획득할 수 있으며, 이는 실제 승마보다 경제적이고 안 전성이 높은 운동 방법으로 제시되고 있다(Shimomura et al., 2009; Sung et al., 2004).

승마 시뮬레이터의 운동 효과는 주로 뇌졸중, 파킨 슨 환자(Han et al., 2012; Kubota et al., 2006; Oh et al., 2014; Yoo et al., 2014; Kim et al., 2008), 뇌성마 비 아동과 장애인(Lee et al., 2011; Oh et al., 2014; Whalen, \& Case-Smith, (2012), 또는 건강한 청·장년층 (Shimomura et al., 2009; Back et al., 2005; Sung et al., 2004; Cho et al., 2012)을 대상으로 하여 검증되어 왔다. 이러한 연구 결과를 종합하여 볼 때, 승마 시뮬 레이터는 안전하고 경제적인 운동 방법으로 활용될 수 있으며, 지속적인 운동이 요구되는 노인에게도 긍 정적인 운동 효과를 나타낼 수 있을 것이다. 그러나 노화로 인하여 심폐기능이 저하되고 근골력계의 협응
능력이 퇴화되어 건강한 일반 젊은 성인과는 다른 자 세조절 전략(Alexander, 1994)과 에너지소비 형태 (Vaughan et al., 1991)의 특징을 보이는 노인에게 선 행연구에서와 같은 운동 효과를 확인할 수 있는지에 대한 검증이 요구되나, 이에 따른 선행연구는 부족한 실정이다. 또한 노인에게 승마 시뮬레이터를 활용한 운동 방법이 효과적일지라도, 노인은 건강한 청·장년 층 보다 로봇을 활용한 시뮬레이션이나 이를 활용한 게임 등을 경험할 수 있는 환경에 노출이 덜 된 집단 이기 때문에 시뮬레이터를 통한 운동이 노인의 체력 뿐 아니라 운동 지속성에 미치는 심리적 요인에 관한 영향에 대해서도 함께 규명해야 할 필요가 있다. 따라 서 본 연구는 승마 시뮬레이터를 활용한 운동이 건강 한 노인에게 미치는 생리적, 심리적 영향에 대하여 규 명하고자 하였다.

\section{연구 방법}

\section{연구 대상}

본 연구의 대상자는 서울 S구에 거주하는 20-30대 건강한 청년 19명과 65 세 이상 건강한 노인 21명으로 총 40 명으로 선정하였다. 대상자는 최근 6 개월 이내에 정형학적, 신경학적, 내과적 이상 소견이 없는 자로 총 40 명이 모집되었다. 모집된 대상자 중 모든 시뮬레이 터 탑승 과제를 수행하지 못한 5명은 중도 탈락하여 청년 18 명, 노인 17 명의 자료가 본 연구에 사용되었다. 대상자의 신체적 특성은 <Table $1>$ 과 같다. 본 연구 는 $\mathrm{K}$ 대학 생명윤리위원회의 승인을 받아 진행하였다.

Table 1. Physical characteristics of participants

\begin{tabular}{ccccc}
\hline Group & $\begin{array}{c}\text { Numbers } \\
\text { of cases }\end{array}$ & $\begin{array}{c}\text { Age } \\
\text { (yrs) }\end{array}$ & $\begin{array}{c}\text { Height } \\
(\mathrm{cm})\end{array}$ & $\begin{array}{c}\text { Weight } \\
(\mathrm{kg})\end{array}$ \\
\hline \hline Young & 18 & 26.4 & 168.9 & 63.4 \\
adult & (F:10, M:8) & \pm 4.2 & \pm 9.2 & \pm 10.8 \\
\hline \hline The & 17 & 68.8 & 160.8 & 65.0 \\
elderly & (F:10, M:7) & \pm 5.5 & \pm 8.4 & \pm 10.1 \\
\hline
\end{tabular}




\section{연구장비}

본 연구에서는 실제 승마와 유사한 효과를 낼 수 있는 승마 시뮬레이터(FORTIS-102, FORTIS사, 한국) <Figure 1> 를 마사학부 교수 1 인, 물리치료학과 교 수 1 인, 체육학 박사 1 인의 전문가 회의를 통하여 선 정하였다. 이 시률레이터는 상하 - 전후 방향으로 구동 이 가능하여 실제 말과 유사한 동작을 생성할 수 있 도록 제작되었으며, 실제 말과의 유사성은 선행연구를 통하여 검증되었다(Park et al., 2014). 본 승마 시뮬레 이터는 대상자 안정성 확보를 위하여 하네스 장착이 가능하도록 설계되었다<Figure 1>.

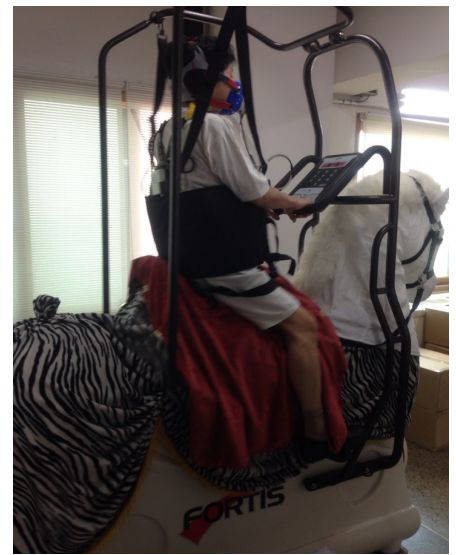

Figure 1. Horse riding simulator with harness

승마 시뮬레이터의 유산소성 운동의 효과 검증을 위하여 시뮬레이터 탑승 동안 실시간으로 산소섭취량, 대사당량 등의 에너지소비를 측정하기 위하여 호흡가 스분석기(K2b2, Cosmed, USA)가 사용되었다.

\section{실험절차}

실제 승마와 유사한 조건에서 시뮬레이터를 탑승하 기 위하여 마사학부 교수 1 인과 기수들이 실제 시뮬레 이터를 탑승 하여 말의 대표적인 보행법인 평보(walk), 느린 속보(slow trot), 빠른 속보(fast trot)와 유사한 보 행패턴이 구현되는 프로그램을 선정하기 위한 전문가 회의를 실시하였다. 이를 통하여 실제 말의 세 가지 보 행 패턴을 가장 유사하게 구현하는 적합한 시뮬레이터
프로그램이 선택되었다. 모든 대상자는 호흡가스 분석 기를 착용한 채로 승마시뮬레이터에 탑승하여 안정 시 에너지소비와 심박 수 측정을 위하여 3분 간 안정 상 태를 유지하였다. 대상자의 안전성 확보를 위하여 기본 승마자세에 대한 사전 교육이 수행되었다. 이후 무작위 로 배정된 세 가지 보행패턴 조건을 각 15 분씩 수행하 였으며 이는 안정시의 에너지소비량과 비교되었다. 각 속도 조건 과제 수행 후에는 심박 수가 안정 시 심박 수로 회복한 이후에 다음 속도 조건을 수행하였다.

\section{자료분석}

유산소성 운동의 효과를 검증하기 위하여 산소섭취 량 $\left(\mathrm{VO}_{2}\right)(\mathrm{ml} / \mathrm{kg} / \mathrm{min})$ 과 운동 강도를 나타내는 지수인 대사당량(metabolic equivalent of task; MET)을 측정 하였다. 이 두 변인은 모두 호흡가스분석기와 연동되 는 프로그램을 통하여 자료를 수집 및 산출하였으며, 항정상태(steady state)의 자료를 활용하기 위하여 총 15 분 동안의 자료 중 마지막 10 분 동안의 평균값을 산출하여 자료 분석에 활용하였다.

본 연구에서는 실제 승마와 승마 시뮬레이터 탑승 시 탑승자의 흥미를 평가하기 위하여 Visual analog scale (VAS)을 사용하였다. VAS는 일반적으로 환자의 통증을 주관적으로 평가하기 위하여 제작된 지표이나(Collins et al., 1997), 대상자의 즉각적인 심리 상태를 측정하기 위 하여 사용되기도 한다(Lee et al., 1991; West et al., 2004). 본 연구에서는 승마 시뮬레이터를 탑승하는 동안 각 보행패턴 과제 수행 직후 과제에 따른 재미와 어려 움을 측정하기 위하여 대상자가 직접 $10 \mathrm{~cm}$ 직선 위에 본인이 느낀 과제의 재미와 어려움 정도를 표기하였다. $0 \mathrm{~cm}$ 에 가까울수록 승마 시뮬레이터 운동은 쉽거나 또는 재미가 없는 것이며, $10 \mathrm{~cm}$ 에 가까울수록 운동이 어렵거 나 재미있는 것으로 정의하였다.

\section{통계처리}

본 연구에서는 승마 시뮬레이터의 보행패턴과 탑승 자의 연령에 따라 승마시뮬레이터 기승이 에너지 소 비량 (단위 체중 당 산소 섭취량과 대사당량)과 지각 
된 과제의 재미 및 어려움에 어떠한 차이가 있는가를 비교하여 승마 시뮬레이터가 노인에게 운동 프로그램 으로 적합한지에 대해 규명하고 그 활용방안에 대해 모색하고자 하였다. 이를 위하여 개체 내 요인을 보행 패턴, 개체 간 요인을 연령으로 한 혼합 설계(mixed design)로 반복측정이 있는 이원 분산분석(two-way repeated measures ANOVA)을 실시하였다(SPSS 19, Chicago, USA). 이때 에너지소비와 관련된 변인은 각 각 휴식, 평보, 느린 속보, 빠른 속보를 포함한 총 4 가 지의 보행패턴과 연령에 따른 $4 \times 2$ 설계로, 지각된 심 리적 요인은 시뮬레이터를 탑승할 때만 측정하였으므 로 휴식 동안을 제외한 3가지의 보행패턴과 연령에 따른 $3 \times 2$ 의 설계로 검증을 진행하였다. 가설 검증을 위한 통계적 유의수준 $(a)$ 은 .05로 설정하였으며, 사후 검정을 위하여 Bonferroni 검정을 실시하였다.

\section{결과}

본 연구는 승마 시뮬레이터 탑승 시의 호흡가스와 VAS 설문지를 측정하여 시뮬레이터의 보행패턴과 연령 의 차이에 따른 에너지소비와 지각된 심리적 요인의 차 이를 규명하고자 하였다. 대부분의 결과는 연령과 관계 없이 시뮬레이터의 보행패턴에 따른 차이가 나타났다. 본 연구 결과에 관한 구체적인 결과는 다음과 같다.

\section{지각된 심리학적 변인의 변화}

승마 시뮬레이터 탑승 동안 관찰된 지각된 과제의 재 미는 보행패턴에 따른 유의한 차이 $(p<05)$ 가 나타났으며 이에 따른 결과는 <Figure $2 \mathrm{~A}>$ 와 같다. 3 가지 보행패턴 중 평보 - 빠른 속보 $(p<05)$ 와 평보 - 느린 속보 $(p<05)$ 간에 유의한 차이가 나타났다. 이는 보다 빠른 보행패턴인 느 린 속보와 빠른 속보가 가장 느린 보행패턴인 평보보다 승마 시뮬레이터 탑승 시 느끼는 지각된 과제의 재미가 높은 것으로 해석할 수 있다. 또한 연령의 차이에 따른 지각된 과제의 재미가 다르게 나타났다( $p<05)$. 사후검정 결과에 따르면 노인 $(6.7 \pm 0.5)$ 이 성인( $4.3 \pm 0.5)$ 에 비해 보다 재밌게 느끼는 것으로 나타났다(p<.05) <Figure $3 \mathrm{~A}$ >
(A)

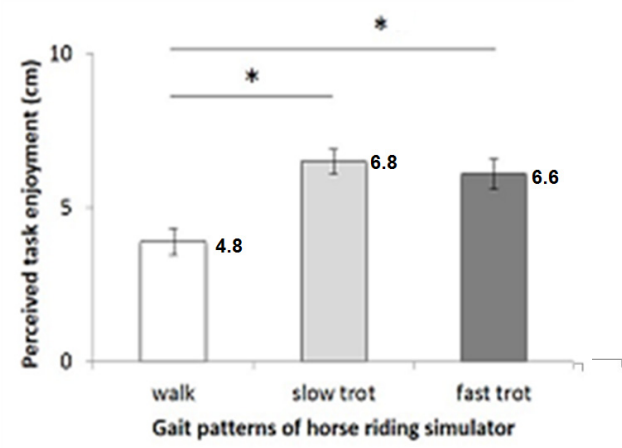

(B)

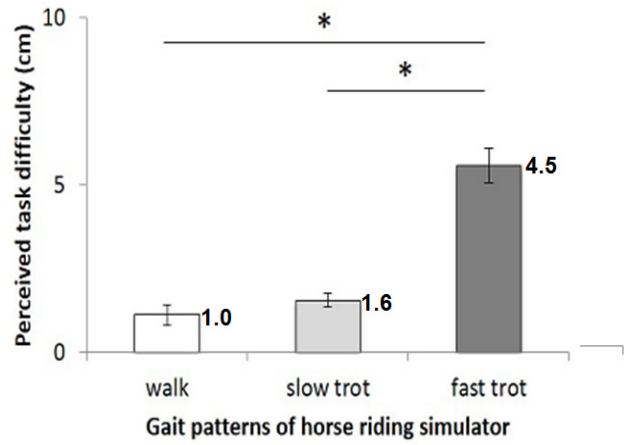

(C)

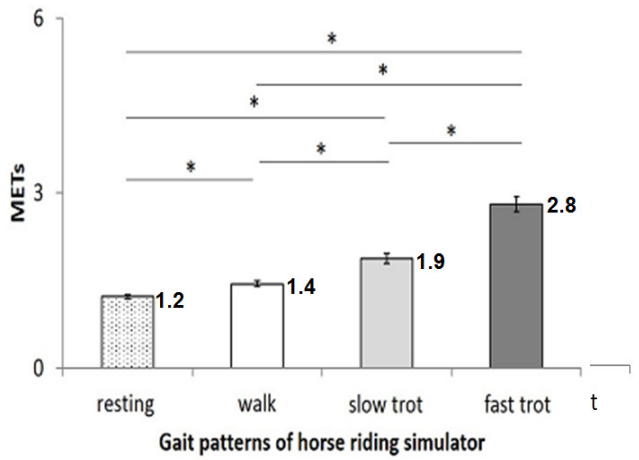

Figure 2. Comparison of (A) peroived task enjoyment, (B) perceived task difficulty, and (C) energy consumption among gait patterns in all participants $\left({ }^{*} p<.05\right)$

또한 지각된 과제의 어려움의 경우에 보행패턴에 따 른 유의한 차이 $(p<.05)$ 가 관찰되었다 <Figure $2 \mathrm{~B}>$. 3 가 지 보행패턴 중 평보 - 빠른 속보 $(p<.05)$, 느린 속보 빠 른 속보 $(p<.05)$ 간에 유의한 차이가 나타났다. 이는 가장 빠른 보행패턴인 빠른 속보가 평보와 느린 속보에 비 해 더 어려운 과제로 지각된 것으로 해석할 수 있다. 반면 지각된 과제의 재미와 달리 연령에 따른 지각된 과제의 어려움의 차이는 관찰되지 않았다<Figure $3 \mathrm{~B}>$. 
Table 2. Comparison of $\mathrm{VO}_{2}$ and METs with respect to gait patterns of horse riding simulator

\begin{tabular}{|c|c|c|c|c|c|c|}
\hline $\begin{array}{c}\text { Gait } \\
\text { coordination } \\
\text { pattern }\end{array}$ & Resting & Walk & $\begin{array}{c}\text { Slow } \\
\text { trot }\end{array}$ & $\begin{array}{l}\text { Fast } \\
\text { trot }\end{array}$ & $F$ & $p$ \\
\hline $\begin{array}{c}\mathrm{VO}_{2} \\
\mathrm{~m} / \mathrm{kg} / \mathrm{min})\end{array}$ & & & & $1.0-0$ & & 5 \\
\hline METs & $1.2 \pm 0.0$ & \pm \pm 0.1 & $1.9 \pm 0$. & $28 \pm 0$. & 131.832 & $<.05$ \\
\hline
\end{tabular}

Table 3. Comparison of $\mathrm{VO}_{2}$ and METs with respect to age difference

\begin{tabular}{ccccc}
\hline Age difference & Young adult The elderly & $F$ & $p$ \\
\hline $\mathrm{VO}_{2}(\mathrm{~m} / \mathrm{kg} / \mathrm{min})$ & $6.7 \pm 0.3$ & $6.2 \pm 0.3$ & 1.494 & 0.23 \\
\hline $\mathrm{METs}$ & $1.9 \pm 0.1$ & $1.8 \pm 0.1$ & 1.494 & 0.23 \\
\hline
\end{tabular}

\section{에너지 소비의 변화}

승마 시뮬레이터 탑승 동안 보행패턴에 따른 산소 섭 취량 $(F=131.83, p<.05)$ 과 대사당량 $(F=131.83, p<.05)$ 은 모 두 보행패턴에 따라 유의한 차이를 나타냈다<Table 2>. 사후검정 결과 모든 보행패턴 조건 간에 유의한 차이가 관찰되었으며 $(p<.05)<$ Figure 20 , 점차 보행패턴이 복잡 해지고 빨라져 과제난이도가 증가하면서 산소 섭취량과 대사당량이 유의하게 상승하는 것을 확인할 수 있다.

그러나 연령의 차이에 따른 산소 섭취량과 대사당 량에 있어서는 청년과 노인들 간에 유의한 차이가 관 찰되지 않았다<Table 3>. 청년의 평균 산소 섭취량은 $6.7 \pm 0.3 \mathrm{ml} / \mathrm{kg} / \mathrm{min}$ 이고, 노인의 평균 산소 섭취량은 $6.2 \pm 0.3 \mathrm{ml} / \mathrm{kg} / \mathrm{min}$ 으로 나타난 것처럼 연령의 차이에 따른 통계적인 유의한 차이는 관찰되지 않았다 $(F=1,494 p=0.23)<$ Figure $3 C$. 또한 연령의 차이에 따른 대사당량의 경우에도 청년의 평균 대사당량은 $1.9 \pm 0.1 \mathrm{MET}$ 으로, 노인의 평균 대사당량인 $1.8 \pm 0.1 \mathrm{MET}$ 와 비슷한 수준으로 나타났다.

\section{논의}

본 연구는 승마 시뮬레이터를 탑승하는 동안의 에 너지소비량의 변화와 지각된 심리학적 요인을 승마 시뮬레이터의 보행패턴과 연령의 차이에 따라 규명하 여 승마 시뮬레이터가 노인들에게 안전하고 경제적인
(A)

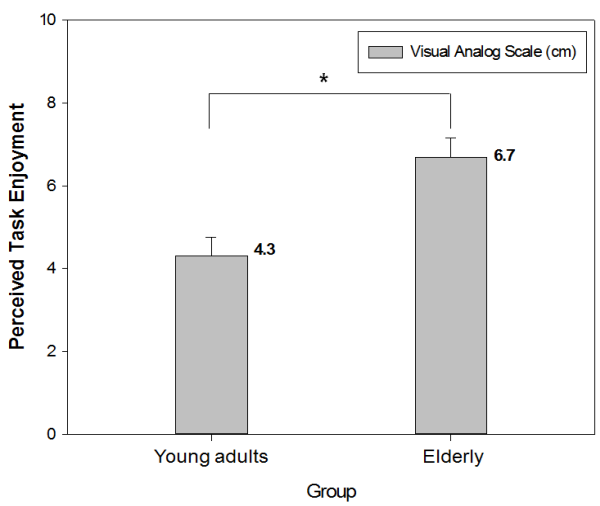

(B)

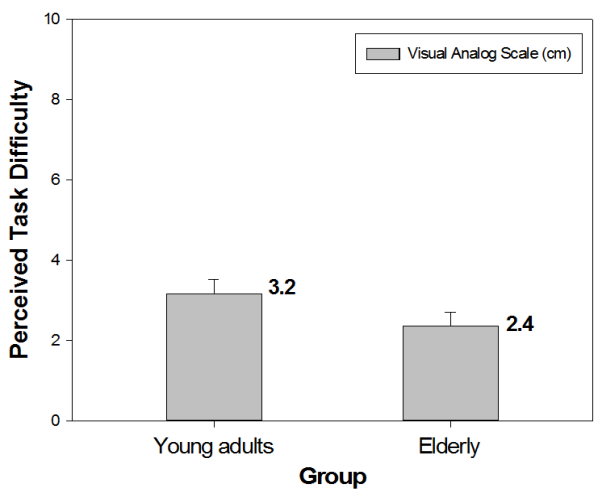

(C)

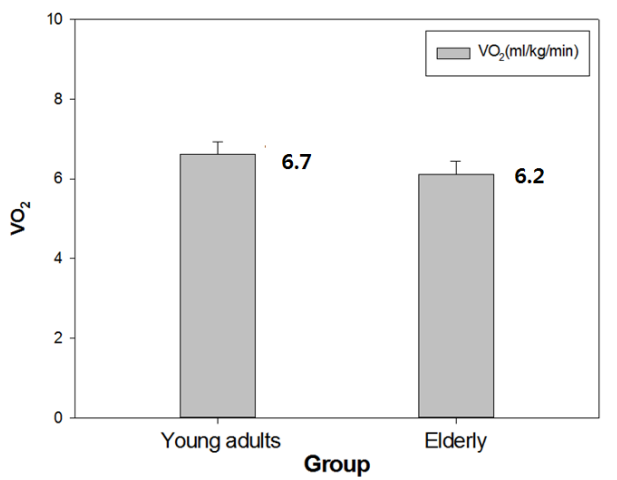

Figure 3. Comparison of (A) perceived task enjoyment, (B) perceived task difficulty and (C) energy expenditure between young adults and the elderly $\left({ }^{\star} p<.05\right)$

유산소성 운동으로 활용될 수 있는지 그 가능성에 대 해 모색하고자 하였다.

연구결과에 따르면 말과 비슷한 보행패턴을 보이는 승마 시뮬레이터를 탑승할 때 대상자들이 연령대에 상관없이 과제의 어려움을 비슷하게 지각한 것으로 나타났다. 즉 과제의 난이도가 증가할수록 탑승자들은 연령과 관계없이 모두 과제가 어렵다고 느꼈다. 반면 에 과제의 난이도가 증가함에도 지각된 과제의 재미 
가 유의하게 향상된 점은 본 시뮬레이터가 탑승자들 에게 흥미를 유발시킨다는 점에서 중요한 지표라 할 수 있다. 일반적으로 과제의 난이도가 증가하면 그에 따른 동기가 저하되는 특징이 나타나게 된다(Huber, 1985). 그러나 본 연구에서 수행한 시뮬레이터 탑승 과제의 난이도는 탑승자가 어렵지 않게 수행해낼 수 있으면서도 충분히 재미를 유발할 수 있는 수준의 난 이도였다. 또한 노인 그룹이 청년 그룹에 비해 높은 지각된 과제의 재미를 보였는데, 이는 로봇을 활용한 게임이나 스포츠 활동에 노인이 청년에 비해 노출이 상대적으로 적을 수 있는 가능성으로 인하여 더 큰 재미를 느낀 것이다. 본 연구에서 선택한 승마 시뮬레 이터의 과제가 비록 낮은 운동 강도이지만 노인들에 게 흥미를 유발시켜 지속적인 운동을 가능하게 한다 면 시뮬레이터 운동을 통하여 노인의 유산소성 체력 을 유지하거나 증진시키는데 활용할 수 있을 것이다. 다만 본 연구에 참여한 노인 중 시뮬레이터 탑승 시 중도 탈락한 대상자가 존재하며 해당 자료는, 결과 분 석에서 제외되었다. 따라서 연구의 결과는 본 연구에 서 선택한 세 가지 시뮬레이터 탑승 과제를 모두 수 행할 수 있는 노인들로 한정시켜서 적용해야 하며, 결 과의 일반화에 주의를 기울여야 할 것이다.

에너지소비 측면에서의 변화는 연령의 차이에 의한 특징은 없었다. 노인은 신체적 노화로 인하여 심폐 기 능이 저하되어 있음에도 불구하고 시뮬레이터 탑승 동 안 청년층과 비슷한 수준의 에너지소비를 보였다. 20대 와 40 대 간의 에너지소비를 비교한 선행연구에서도 이 와 비슷한 연구결과가 제시되었으며(Sung et al., 2004). 이는 승마 시뮬레이터 탑승이 연령에 관계없이 비슷한 수준의 운동효과를 보이는 것으로 해석할 수 있을 것이 다. 노인은 청년에 비해 근력이 약하고, 심폐기능이 저 하되는 특징을 보이지만, 승마 시뮬레이터를 탑승하는 운동을 수행함으로써 청년과 비슷한 수준의 운동 효과 를 볼 수 있을 것이다. 대사당랑 측면에서 살펴보면 본 연구에서 가장 난이도가 높은 과제인 빠른 속보는 약 $3 \mathrm{METs}$ 로 저강도 운동에 해당한다. 그러나 본 연구에서 사용한 시뮬레이터가 아닌 전-후 방향으로만 단순하게 움직임을 반복하는 다른 승마 시뮬레이터를 탑승한 청 년층의 평균 대사당량이 $2 \mathrm{METS}$ 던 선행연구 결과와 비 교해보았을 때 (Shimomura et al., 2009), 본 연구에서
사용한 시뮬레이터 운동의 효과는 그보다 높은 편이라 할 수 있다. 승마 시뮬레이터를 탑승하는 동안 과제의 난이도는 평보에서 빠른 속보까지 속도가 점차 증가하 는 패턴으로 변화하는 동안에 통계적으로 유의한 차이 는 있었으나 모든 속도 조건에서 저강도의 운동 효과를 보였으며, 이로 인하여 청년 그룹과 노인 그룹 간의 운 동효과가 동일하게 나타난 것으로 사료된다. 그러나 속 도가 증가함에 따라 보행패턴에 따른 유의한 산소섭취 량과 대사당량의 유의한 차이가 나타난 결과에 따르면, 저강도의 운동 효과라도 시뮬레이터의 속도에 따라서 그 효과는 차이가 날 수 있다. 실제 승마를 하는 동안 말 보행의 속도가 증가하고 복잡해짐에 따라 탑승자의 에너지소비량이 증가한 선행연구의 결과로 미루어볼 때 (Devienne, \& Guezennec, 2000; Westerling, 1983), 이 는 승마 시뮬레이터가 실제 승마와 유사한 효과를 보이 는 것으로 이해할 수 있을 것이다.

즉, 보행패턴이 보다 빠르고 복잡해지면서 산소 섭취 량이나 대사당량에서는 각 보행패턴에 따른 유의한 차 이가 나타났으며, 각 보행패턴 조건마다 운동의 효과가 다른 것을 확인할 수 있었다. 따라서 보행패턴에 따라 약 1.5 3METs의 에너지소비를 보이는 승마 시뮬레이터 는 노인과 성인 대상자 모두에게 적합한 운동효과를 줄 수 있을 것으로 기대한다.

\section{결론 및 제언}

말의 보행패턴을 유사하게 구현하는 승마 시뮬레이 터를 탑승할 때 과제의 난이도가 증가함에 따라 에너지 소비량과 지각된 과제의 재미와 어려움이 증가되었으 며, 특히 지각된 과제의 재미에 있어 노인이 청년보다 더 재밌게 느꼈다. 이러한 결과를 종합하여 볼 때, 본 연구에서 사용된 승마 시뮬레이터는 노인을 위한 저강 도 유산소 운동의 대안으로 사용될 수 있을 것으로 기 대한다. 또한 노인들이 승마 시뮬레이터 탑승을 재밌게 느끼는 것은 운동에 대한 흥미를 유발시킬 수 있는 중 요한 요인으로 작용할 것으로 사료되며, 승마 시뮬레이 터를 통하여 노인들이 지속적으로 안전하게 승마 운동 에 참여할 수 있는 방법으로 활용될 수 있을 것이다. 
향후 후속 연구에서는 본 승마 시뮬레이터와 실제 말 을 탑승할 때에 직접적으로 작용하는 근육의 활성화 정 도를 측정하여 승마 시뮬레이터가 에너지소비 뿐 아니 라 근력 강화 및 자세조절에 미치는 효과 검증이 필요 할 것으로 본다. 이를 통하여 안전하고 경제적인 승마 시뮬레이터가 노인과 근골격계 질환자에게 적용될 수 있는 운동요법으로 활용될 수 있기를 기대하는 바이다.

\section{참고문헌}

Alexander, N. B. (1994). Postural control in older adults. Journal of the American Geriatrics Society. 42(1): 93-108.

All, A. C, Loving, G. L., \& Crane, L L (1999). Animals, horseback riding, and implications for rehabilitation therapy. Journal of Rehabilitation, 65(3): 49-53.

Araujo, T. B., Silva, N. A, Costa, J. N., Pereira, M. M, \& Safons, M. P. (2011). Effect of equine-assisted therapy on the postural balance of the elderly. Brazilian Journal of Physical Therapy, 15(5): $414-419$.

Baek, J. H., Sung, B. J., \& Lee, B. W. (2005). The Analysis of Electromyogram in Horse Riding Simulator. Journal of Sport and Leisure Studies, 23: 341-352.

Bertoti, D. B. (1988). Effect of therapeutic horseback riding on posture in children with cerebral palsy. Physical Therapy, 68(10): 1505-1512.

Bizub, A. L, Joy, A, \& Davidson, L (2003). "It's like being in another world": Demonstrating the benefits of therapeutic horseback riding for individuals with psychiatric disability. Psychiatric Rehabilitation Journal, 26(4): 377-384.

Byeon, Y. H., Lee, M. Y., Lee, J. N., \& Kwak, K. C. (2013). A trends analysis of domestic research in developing horse riding simulator. Institute of Control, Robotics and System annual conference Abstracts, 28: 414-415.

Cho, W. S., Kim, Y. N., Park, J. S., \& Jin, H. K., (2012). The Effects of Ability to Balance Posture and Proprioception by Horse Riding Simulator and Galvanic Vestibular Stimulation. Physical Therapy Korea, 19(2): 39-47.

Collins, S. L., Moore, R. A., \& MaQuay, H. J. (1997). The visual analogue pain intensity scale: what is moderate pain in millimetres?. Pain, 72(1): 95-97.

de Araújo, T. B., de Oliveira, R. J., Martins, W. R., de Moura Pereira, M, Copetti, F., \& Safons, M. P. (2013). Effects of hippotherapy on mobility, strength and balance in elderly. Archives of Gerontology and Geriatrics, 56(3): 478-481.

Devienne, M.-F., \& Guezennec, C.-Y. (2000). Energy expenditure of horse riding. European Journal of Applied Physiology, 82(5-6): 499-503.

Fitzpatrick, J., \& Tebay, J. (1998). Hippotherapy and therapeutic riding: An international review. Companion Animals in Human Health, 41-58.

Granados, A. C., \& Agís, I. F. (2011). Why children with special needs feel better with hippotherapy sessions: A conceptual review. The Journal of Alternative and Complementary Medicine, 17(3): 191-197.

Han, J. Y., Kim, J. M., Kim, S. K., Chung, J. S., Lee, H. C., Lim, J. K., Lee, J. K. \& Park, K. Y. (2012). Therapeutic effects of mechanical horseback riding on gait and balance ability in stroke patients. Annals of Rehabilitation Medicine, 36(6): 762-769.

Homnick, D. N, Henning, K M, Swain, C. V., \& Homnick, T. D. (2013). Effect of therapeutic horseback riding on balance in community-dwelling older adults with balance deficits. The Journal of Alternative and Complementary Medicine, 19(7): 622-626.

Hosaka, Y., Nagasaki, M, Bajotto, G, Shinomiya, Y., Ozawa, T., \& Sato, Y. (2010). Effects of daily mechanical horseback riding on insulin sensitivity and resting 
metabolism in middle-aged type 2 diabetes mellitus patients. Nagoya Journal of Medical Science, 72(34): 129-137.

Huber, V. L (1985). Effects of task difficulty, goal setting, and strategy on performance of a heuristic task Journal of Applied Psychology, 70(3): 492-504.

Kendall, E., Maujean, A., Pepping, C. A., \& Wright, J. J. (2014). Hypotheses about the Psychological Benefits of Horses. Explore: The Journal of Science and Healing, 10(2): 81-87.

Kim, D. H., Kim. S. J., Bae, S. S, \& Kim. K. (2008). The Effect of Indoor Horseback-Riding Machine on the Balance of the Elderly with Dementia. Journal of Korea Society of Physical Medicine, 3(4): 235-246.

Kubota, M., Nagasaki, M., Tokudome, M., Shinomiya, Y., Ozawa, T., \& Sato, Y. (2006). Mechanical horseback riding improves insulin sensitivity in elder diabetic patients. Diabetes Research and Clinical Practice, 71(2): 124-130.

Lee, D. R., Lee, N. G., Cha, H. J., O, Y. S., You, S. H., Oh, J. H., \& Bang, H. S. (2011). The effect of robo-horseback riding therapy on spinal alignment and associated muscle size in MRI for a child with neuromuscular scoliosis: An experimenter-blind study. NeuroRehabilitation, 29(1): 23-27.

Lee, K. A., Hicks, G., \& Nino-Murcia, G. (1991). Validity and reliability of a scale to assess fatigue. Psychiatry Research, 36(3): 291-298.

Oh, H. W., Lee, M G., Jang, J. Y., Jin, J. J., Cha, J. Y., Jin, Y. Y., \& Jee, Y. S. (2014). Time-ffects of horse simulator exercise on psychophysiological responses in men with chronic low back pain. Isokinetics and Exercise Science, 22(2): 153-163.

Park, J. H., Shurtleff, T., Engsberg, J., Rafferty, S., You, J. Y., You, I. Y., \& You, S. H. (2014). Comparison between the robo-horse and real horse movements for hippotherapy. Bio-medical Materials and Engineering, 24(6):
2603-2610.

Shimomura, K., Murase, N., Osada, T., Kime, R., Anjo, M., Esaki, K., Shiroishi, K., Hamaoka, T., \& Katsumura, T. (2009). A study of passive weight-bearing lower limb exercise effects on local muscles and whole body oxidative metabolism: A comparison with simulated horse riding, bicycle, and walking exercise. Dynamic Medicine, 8(1): 4-11.

Silver, J. (2002). Spinal injuries resulting from horse riding accidents. Spinal Cord, 40(6): 264-271.

Sterba, J. A., Rogers, B. T., France, A. P., \& Vokes, D. A. (2002). Horseback riding in children with cerebral palsy: effect on gross motor function. Developmental Medicine \& Child Neurology, 44(5): 301-308.

Sung, B. J., Chung, D. S., Kim, B. H., Back, J. H., Ko, B. G., \& Lee, E. J., (2004). The change of HR, $\mathrm{VO}_{2}, \mathrm{VE}, \mathrm{MET}$ and Calory expenditure in Horseback-Riding Simulator's Walking Types. Korean Journal of Sport Science, 15(1): 1-13.

Vaughan, L., Zurlo, F., \& Ravussin, E. (1991). Aging and energy expenditure. The American Journal of Clinical Nutrition, 53(4): 821-825.

Westerling, D. (1983). A study of physical demands in riding. European Journal of Applied Physiology and Occupational Physiology, 50(3): 373-382.

West, J., Otte, C, Geher, K, Johnson, J., \& Mohr, D. C. (2004). Effects of Hatha yoga and African dance on perceived stress, affect, and salivary cortisol. Anmals of Behavioral Medicine, 28(2): 114-118.

Whalen, C. N., \& Case-Smith, J. (2012). Therapeutic effects of horseback riding therapy on gross motor function in children with cerebral palsy: A systematic review. Physical \& Occupational Therapy in Pediatrics, 32(3): 229-242.

Yoo, J. H., Kim, S. E., Lee, M. G., Jin, J. J., Hong, J., Choi, Y. T., Kim, M. H., \& Jee, Y. S. (2014). The effect of horse simulator riding on visual analogue scale, body composition 
and trunk strength in the patients with chronic low back pain. International Journal of Clinical Practice, 68(8): 941-949.

Zadnikar, M, \& Kastrin, A. (2011). Effects of hippotherapy and therapeutic horseback riding on postural control or balance in children with cerebral palsy: A meta-analysis. Developmental Medicine \& Child Neurology, 53(8): 684-691. 
